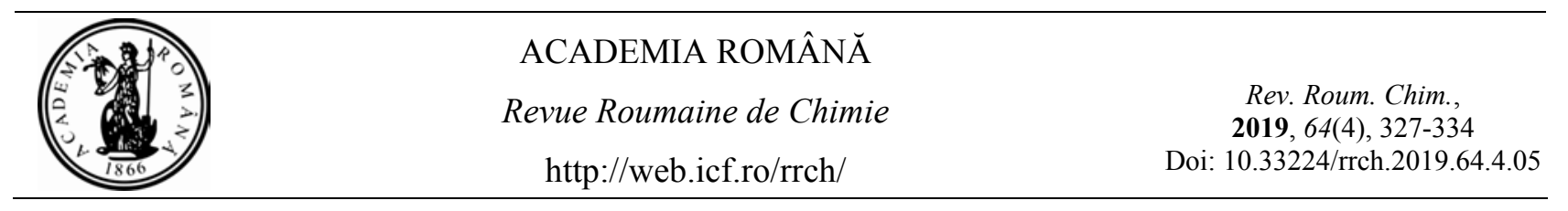

\title{
DEVELOPMENT AND CHARACTERIZATION OF GELATIN/CHITOSAN/MONTMORILLONITE COMPOSITE SCAFFOLD ENRICHED WITH MAGNESIUM
}

\author{
Aysel KOÇ DEMİR \\ Ankara University Faculty of Science, Tissue Engineering, Biomaterials and Nanobiotechnology Laboratory, \\ Tandogan 06100, Ankara, Turkey
}

Received January 5, 2017

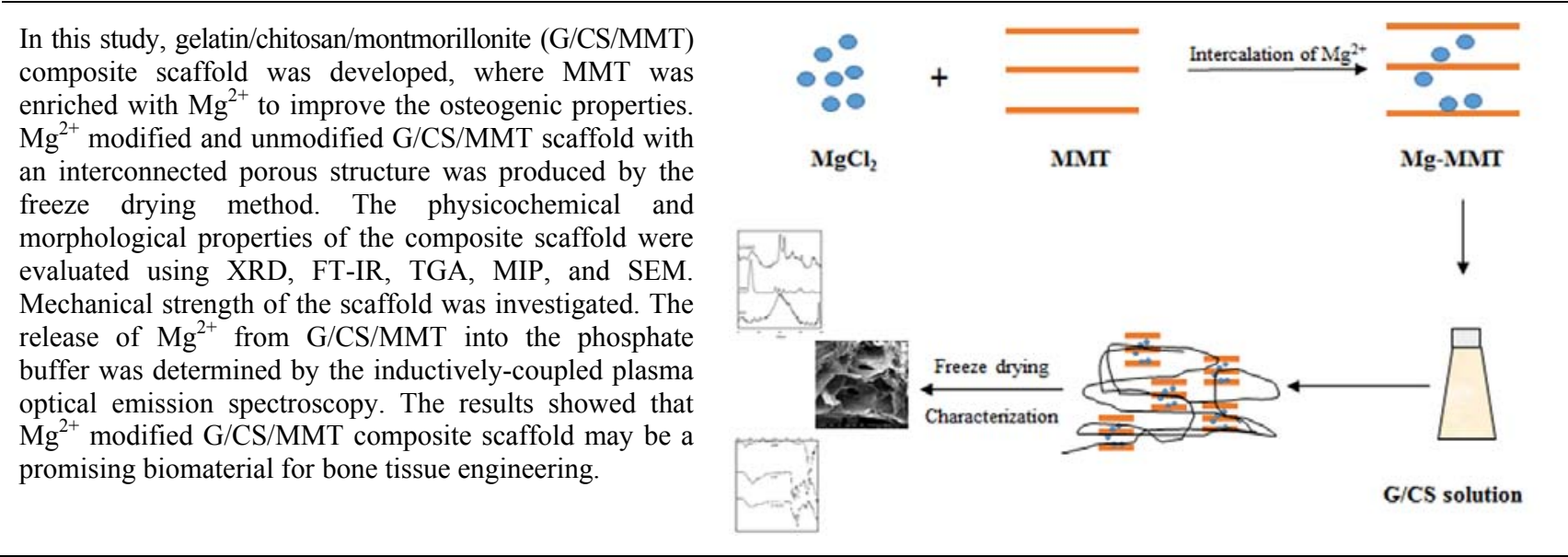

\section{INTRODUCTION}

Development of an ideal scaffold for bone tissue engineering applications is an ongoing goal for the biomaterials scientists. Multifunctional composite biomaterials could serve as temporary templates if they could successfully mimic the aspects of the natural bone, and act as the mineralized artificial extracellular matrix (ECM) guiding new tissue formation. To achieve this, apart from being osteogenic, the composite material should possess biocompatibility, biodegradability, adequate mechanical efficiency, highly interconnected porous structure with appropriate pore size and surface topography.

\footnotetext{
${ }^{*}$ Corresponding author: akocaysel@yahoo.com (A. Koç Demir)
}

From bone tissue engineering point of view, the determination of appropriate materials and the fabrication method are the crucial steps. Materials widely used in bone tissue engineering include natural and synthetic polymers and ceramics. Natural polymers are generally preferred to synthetic ones due to their biological response and degradation properties in the human body. ${ }^{1,2}$ It is well known that among numerous natural polymers, chitosan (CS) and gelatin $(\mathrm{G})$ are considered as promising polymers because of their non-toxicity, excellent biocompatibility and biodegradability. ${ }^{3} \mathrm{CS}$ is one of the most studied biological polymer. It is a linear polysaccharide obtained from partial deacetylation of chitin. ${ }^{4}$ The chemical structure of chitosan is composed of repeating units of glucosamine and 
$\mathrm{N}$-acetyl glucosamine, and its structure resembles glycosaminoglycans. ${ }^{5}$ Gelatin is the denaturated protein derived from native collagen via hydrolysis. Its structure contains RGD (L-arginine-glycine-Laspartic acid)-like sequences of amino acids, therefore gelatin facilitates cell adhesion and proliferation and also exhibits good biocompatibility. ${ }^{6}$

Biomaterials created by blending chitosan and gelatin have been investigated for various applications. $^{7}$ This blend is generally combined with a number of different types of inorganic and bioactive fillers to create a promising bone tissue engineering scaffold. As inorganic filler, clay has been considered as a good choice due to its unique properties, such as high surface area, swelling capacity and cation exchange capacity. ${ }^{8}$ Among natural smectite clay minerals, the most commonly used one for the preparation of polymer composites is the montmorillonite (MMT). This is related to its distinguished properties, i.e. high surface area, swelling capacity, high value of cation exchange capacity, etc. MMT is a 2:1 (TOT) clay mineral, composed of an octahedral layer (O) entering between the two tetrahedral layers (T). Isomorphic substitution within layers $\left(\mathrm{Al}^{3+}\right.$ replaced by $\mathrm{Si}^{4+}$ or $\mathrm{Mg}^{2+}$ ) will cause an increase in the net negative charge on the surface of MMT. Excess negative charge in the layers of TOT are generally balanced by the alkali earth cations, as $\mathrm{K}^{+}, \mathrm{Na}^{+}, \mathrm{Ca}^{2+}$ and also with other positively charged ions.

Trace elements found in bone (magnesium, zinc, strontium) are known to be necessary for healthy growth, development and functioning of the bone. They are involved in bone modeling and remodeling via activating different signalling pathways in the bone cells. For that reason, the treatment of cells with these ions is essential. From this point, developing functional biomaterials capable of releasing osteogenic ions is crucial to promote bone formation around the implant. MMT may be considered as an 'ion reserve', and can be enriched with osteogenic ions, such as $\mathrm{Mg}$, $\mathrm{Sr}$, or $\mathrm{Zn}$ to enhance its osteogenic capacity.

While there are reports on G/CS/MMT composites as scaffold biomaterial, magnesiumenriched MMT in this tri-component system has not received sufficient interest in the literature. In this study, we aimed to combine the benefits of $G$, CS, MMT and magnesium to develop an osteogenic scaffold for bone tissue engineering. Composite scaffolds produced via freeze drying method were characterized in detail, using X-ray powder diffraction spectroscopy (XRD), fourier transform infrared spectroscopy (FT-IR), thermal gravimetric analysis (TGA), mercury intrusion porosimetry (MIP) and scanning electron microscopy (SEM). The release of $\mathrm{Mg}^{2+}$ from the scaffolds into phosphate buffer was determined by inductively-coupled plasma optical emission spectroscopy (ICP-OES). The swelling properties and mechanical properties of the scaffolds were also evaluated.

\section{EXPERIMENTAL}

\section{Materials}

CS of medium molecular weight $(\mathrm{Mr} \sim 400,000 ;>85 \%$ deacetylation) and gelatin (type B from bovine skin) were purchased from Sigma-Aldrich (St. Louis, MO). All other chemicals were of reagent grade (Sigma), and used without further purification. Montmorillonite with a cation exchange capacity (CEC) of $87.5 \mathrm{meq} / 100 \mathrm{~g}$ was obtained from Samas Company (Resadiye, Tokat, Turkey).

\section{Preparation and characterization of Mg-modified MMT}

Montmorillonites enriched with $\mathrm{Mg}^{2+}$ were prepared as described previously. ${ }^{9}$ Briefly, dispersed MMT was stirred magnetically at room temperature for $24 \mathrm{~h}$. Then, magnesium chloride solutions at concentrations equivalent to either 1,2 or 4 times of CEC of clay were prepared and added into MMT solutions. The stirring was continued for an additional $12 \mathrm{~h}$ to obtain a homogeneous mixture. Consequently, the mixture was transferred into centrifuge tubes and the resulting $\mathrm{Mg}$ enriched MMT was collected by centrifugation. The pellet was rinsed several times in distilled water until the Cl-test was negative. The products were dried for 2 days in an oven at $100^{\circ} \mathrm{C}$.

The crystal phases of the samples were determined by a D8 Advance model X-ray powder diffractometer (Bruker, Karlsruhe, Germany) using a monochromatic $\mathrm{Cu}-\mathrm{K} \alpha$ radiation.

The elemental analyses were carried out using a Spectro X-Lab 2000 model polarized energy dispersive XRF spectrometer (Kleve, Germany).

Specific surface area measurements of the samples were performed by the Brunauer, Emmett and Teller (BET) method of adsorption of nitrogen gas at $77 \mathrm{~K}$ using a Quantachrome Nova 2200 model analyzer (Boynton Beach, FL). The samples were outgassed at $110^{\circ} \mathrm{C}$ for $4 \mathrm{~h}$ prior to $\mathrm{N}_{2}$ adsorption.

\section{Preparation of G/CS/MMT composite scaffolds}

Composite scaffolds were produced through freeze drying method. Briefly, chitosan was dissolved in $2 \%$ acetic acid to obtain a $2 \mathrm{wt}-\%$ solution, and then required amount of gelatin was added to the chitosan solution in 1:2 ratio. The solution was mixed at $50^{\circ} \mathrm{C}$ and then, Mg-modified and not nonmodified it should be "natural" MMT were introduced to the gelatin-chitosan solution and stirred at moderate speed overnight to get a perfectly homogenous solution. Then, $0.25 \%$ glutaraldehyde solution was added dropwise into the solution with vigorous stirring at $40^{\circ} \mathrm{C}$ for an additional $20 \mathrm{~min}$. The obtained product was poured into well culture 
plates and frozen at $-80^{\circ} \mathrm{C}$ for $12 \mathrm{~h}$, followed by freeze drying in Alpha 1-4 LD model lyophilizer (Christ, Germany) for 24 h. After treating with $1 \%$ sodium hydroxide and 3\% sodium borohydride aqueous solutions, the samples were lyophilized again. The synthesized scaffolds were stored in an airtight container until they were used for further analysis.

\section{Characterization of composite scaffolds}

The crystal phase of composite scaffold before and after modification was analyzed with an XRD spectrometer (Bruker) using a monochromatic $\mathrm{Cu}-\mathrm{K} \alpha$ radiation.

The structural analysis of composite scaffold was evaluated by FTIR spectroscopy in the spectral range of 400 $4000 \mathrm{~cm}^{-1}$ using a Spectrum 100 model instrument (Perkin Elmer, Waltham, MA).

The thermal degradation and thermal stability of the biomaterials were investigated by TGA analysis using a Shimadzu DTG-60H model instrument (Kyoto, Japan).

The architecture and surface structure of the obtained composite scaffolds were examined by SEM using a Gemini 1525 FEGSEM model instrument (Cambridge, U.K.).

The pore size distribution of the scaffolds was determined by mercury intrusion porosimetry using a Poremaster 60-model instrument (Quantachrome Corp., Hook, U.K.).

The water absorption capacity of the scaffolds was performed in phosphate-buffered saline (PBS, pH 7.4) at $37^{\circ} \mathrm{C}$. Briefly, the weighed dry scaffold $\left(\mathrm{W}_{\mathrm{o}}\right)$ was placed in PBS and the sample was removed from the PBS solution at predetermined time points, and the wet weight was measured $\left(\mathrm{W}_{\mathrm{w}}\right)$. The ratio of swelling was calculated using the following equation:

Swelling ability $(\%)=\left[\left(\mathrm{W}_{\mathrm{w}}-\mathrm{W}_{\mathrm{o}}\right) / \mathrm{W}_{\mathrm{o}}\right] \times 100$

The compressive strength of the samples was measured by a Shimadzu AGS-X model universal compression testing instrument (Duisburg, Germany) under a $0.7 \mathrm{~N}$ load cell at a constant strain speed of $2 \mathrm{~mm} / \mathrm{min}$.

The release of $\mathrm{Mg}$ from the scaffolds into PBS was determined using an Optima 4300D model ICP-Optical Emission Spectrometer (Perkin Elmer, Waltham, MA). The samples inside wells of culture plates were incubated in PBS at $37^{\circ} \mathrm{C}$ for up to 7 days.

\section{RESULTS AND DISCUSSION}

\section{XRD, XRF and BET evaluation of modified MMTs}

To determine the appropriate ratio of $\mathrm{Mg}^{2+}$ to be incorporated into the MMT structure, the $\mathrm{MgCl}_{2}$ modified samples were characterized by XRD and $\mathrm{XRF}$ analyzes.

The XRD patterns of the natural MMT and the modified MMT are given in Fig. 1. The interlayer distance (d-spacing) of the MMTs were obtained from the peak positions in $\mathrm{x}$-ray diffraction patterns and calculated using Bragg's equation $(\mathrm{n} . \lambda=2 \mathrm{~d} \cdot \sin \theta)$. The $2 \theta$ values and the distance between layers (d) were determined for natural
MMT and modified MMT and the results are given in Table 1. The values showed that the distance of d (001) did not change very much due to the interposition of the cations between the layers, but the peak intensities increased slightly compared to the natural MMT. The results showed that the crystal structure of the clay is strengthened by the cations entering into the structural layers.

The Mg content of natural MMT and modified MMT structures were determined by XRF. Results showed that the amount of $\mathrm{Mg}^{2+}$ intercalated into the MMT structure was found to be $1.7621 \%$, $1.7696 \%, 3.4006 \%$ and $3.7130 \%$, for the natural MMT $\operatorname{Mg}(0 \mathrm{x})-\mathrm{MMT}, \quad \operatorname{Mg}(1 \mathrm{x})$-MMT, $\operatorname{Mg}(2 \mathrm{x})$ MMT and $\operatorname{Mg}(4 \mathrm{x})-\mathrm{MMT}$, respectively. It was found that the amount of $\mathrm{Mg}$ intercalated into the layer structure of MMT increases by the increase in ion concentration. Four times ratio of $\mathrm{Mg}^{2+}$ was found to be suitable for use throughout the study.

The BET surface area and total pore volume of MMT were $43.939 \mathrm{~m}^{2} \mathrm{~g}^{-1}$ and $6.651 \times 10^{-2} \mathrm{~cm}^{3} \mathrm{~g}^{-1}$, while the BET surface area and total pore volume of $\mathrm{Mg}(4 \mathrm{x})$-MMT were $35.720 \mathrm{~m}^{2} \mathrm{~g}^{-1}$ and $7.439 \times 10^{-2}$ $\mathrm{cm}^{3} \mathrm{~g}^{-1}$, respectively. According to results, it can be concluded that the surface area of MMT is decreased by the addition of magnesium.

\section{Structural evaluation of G/CS/MMT composite scaffolds}

The observation of the characteristic peaks of MMT and G/CS in the XRD patterns of the G/CS/MMT composite scaffold showed that positively charged $\mathrm{G} / \mathrm{CS}$ intercalated into clay layers and G/CS/MMT composite structures were successfully formed (Fig. 2a).

The characteristic peaks of MMT [3600-3350 $\mathrm{cm}^{-1}$ (OH stretching); $1000 \mathrm{~cm}^{-1}$ (Si-O stretching)] and G/CS $\left[3476 \mathrm{~cm}^{-1}\right.$ (OH stretching); $2923 \mathrm{~cm}^{-1}$ (CH stretching); $1637 \mathrm{~cm}^{-1}$ (amide I) and $1071 \mathrm{~cm}^{-1}$ (CO tension)] were found in the spectra of $\mathrm{G} / \mathrm{CS} / \mathrm{MMT}$ indicating that composite scaffold was successfully obtained by incorporation of $\mathrm{G} / \mathrm{C}$ with MMT (Fig. 2b).

It is well known that incorporation of inorganic fillers into polymer matrices positively influence the thermal properties of the polymer. ${ }^{10}$ The TGA curves of MMT, G/CS and G/CS/MMT are shown in Fig. 3. The first mass loss for MMT was observed at $100^{\circ} \mathrm{C}$ due to the desorption of water. The mass loss of MMT was not significantly changed by the increase in temperature. On the other hand, the mass loss for G/CS occurred at 
about $250^{\circ} \mathrm{C}$, and this value increased to about $88 \%$ as the temperature increased. It was found that the thermal degradation properties of the composite material obtained by the addition of
MMT had increased about $50 \%$, indicating the positive effect of the inorganic filler to the polymer.

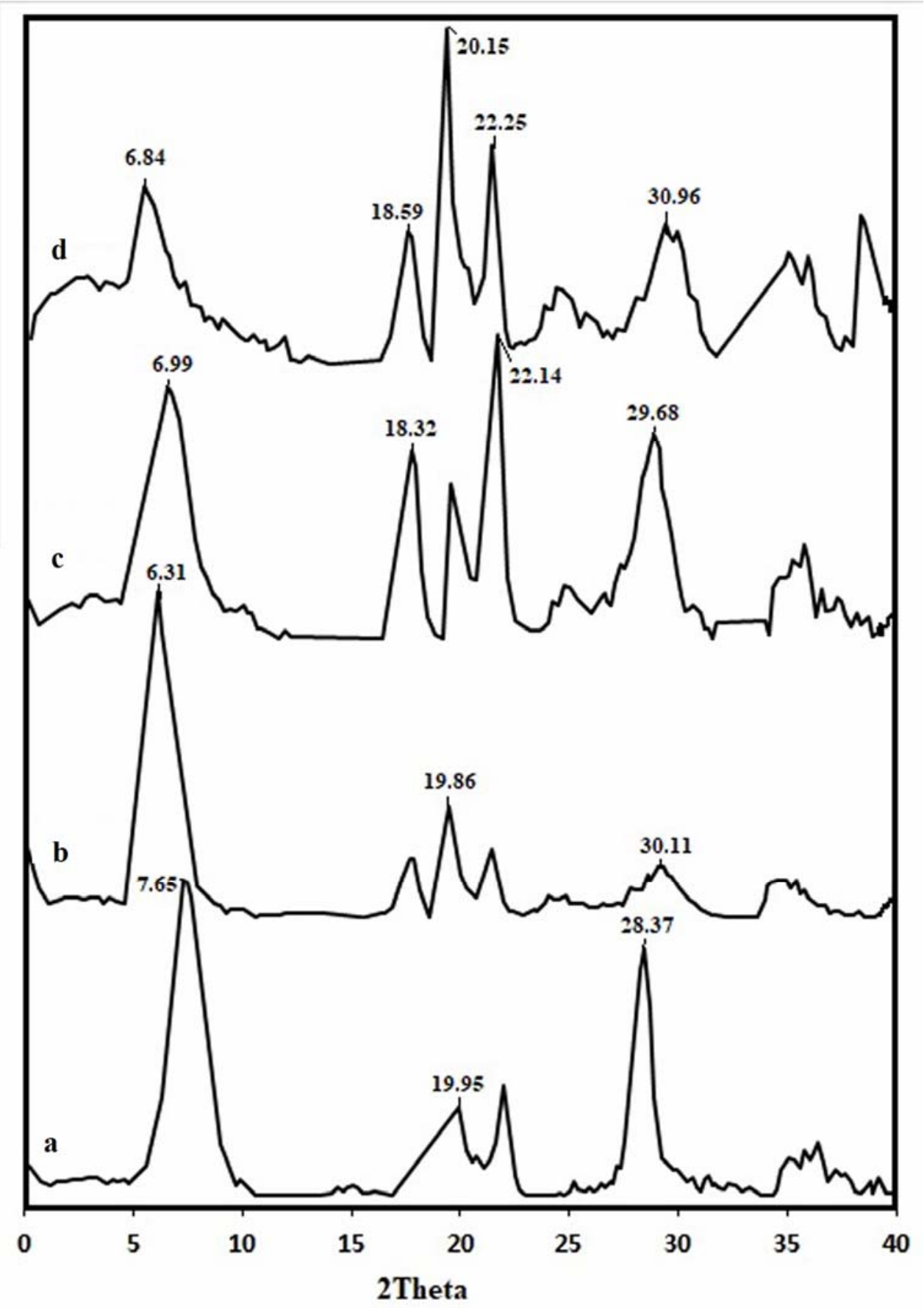

Fig. 1 - X-ray diffraction patterns of (a) natural MMT $(\operatorname{Mg}(0 \mathrm{x})-\mathrm{MMT}),(\mathrm{b}) \mathrm{Mg}(1 \mathrm{x})-\mathrm{MMT}$, (c) $\operatorname{Mg}(2 x)-M M T$, and (d) $\operatorname{Mg}(4 x)-M M T$.

\section{Table 1}

The BET specific surface areas (A) and specific pore volumes $(\mathrm{V})$ of MMT and $\mathrm{Mg}(4 \times)$-MMT

\begin{tabular}{lll}
\hline Sample & $\mathrm{A}\left(\mathrm{m}^{2} \mathrm{~g}^{-1}\right)$ & $\mathrm{V}\left(\mathrm{cm}^{3} \mathrm{~g}^{-1}\right)$ \\
\hline MMT & 43.939 & $6.651 \times 10^{-2}$ \\
$\operatorname{Mg}(4 \times)$-MMT & 35.720 & $7.439 \times 10^{-2}$ \\
\hline
\end{tabular}



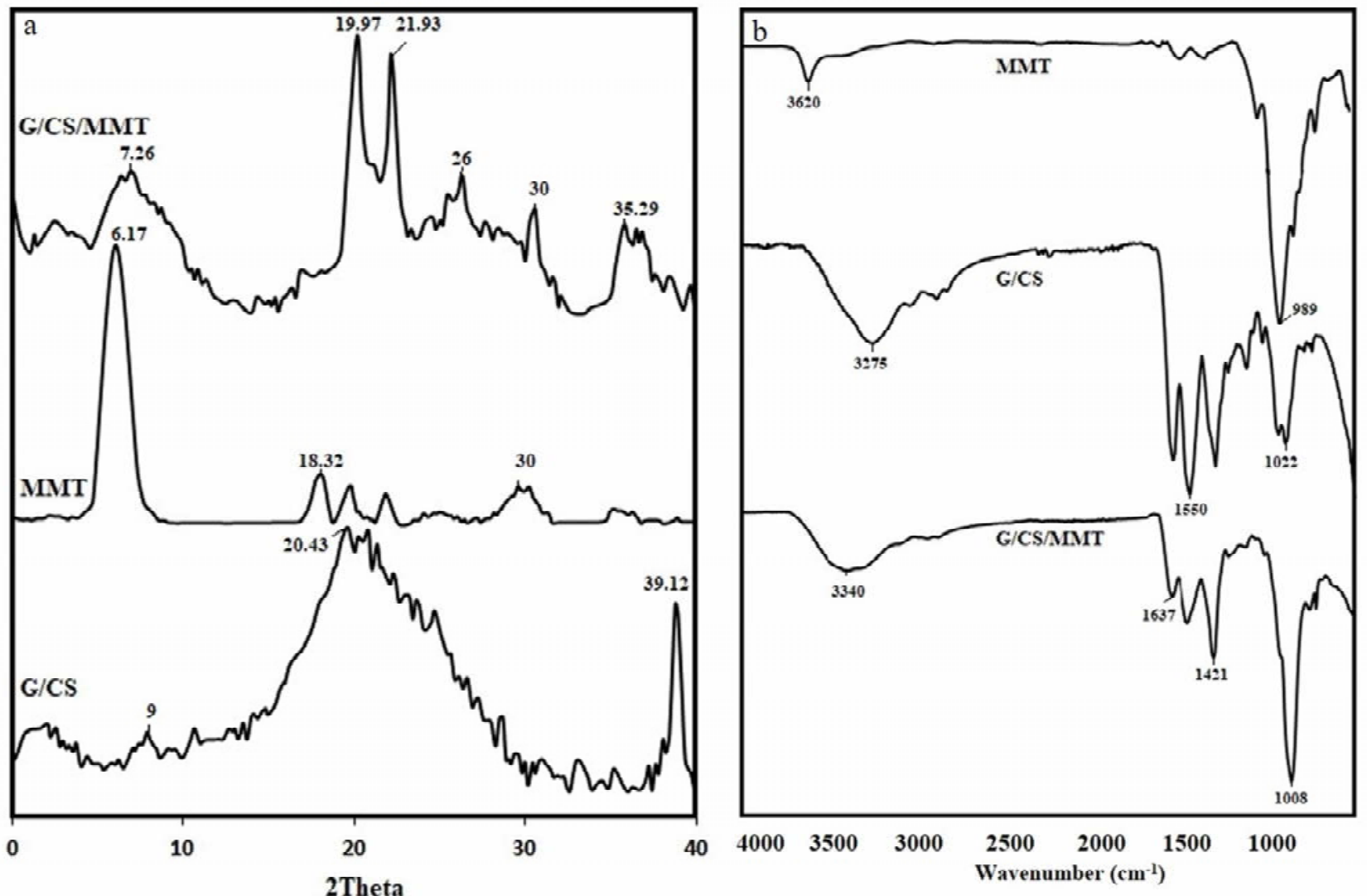

Fig. 2 - (a) X-ray diffraction patterns, and (b) FTIR spectra of G/CS, MMT and G/CS/MMT.

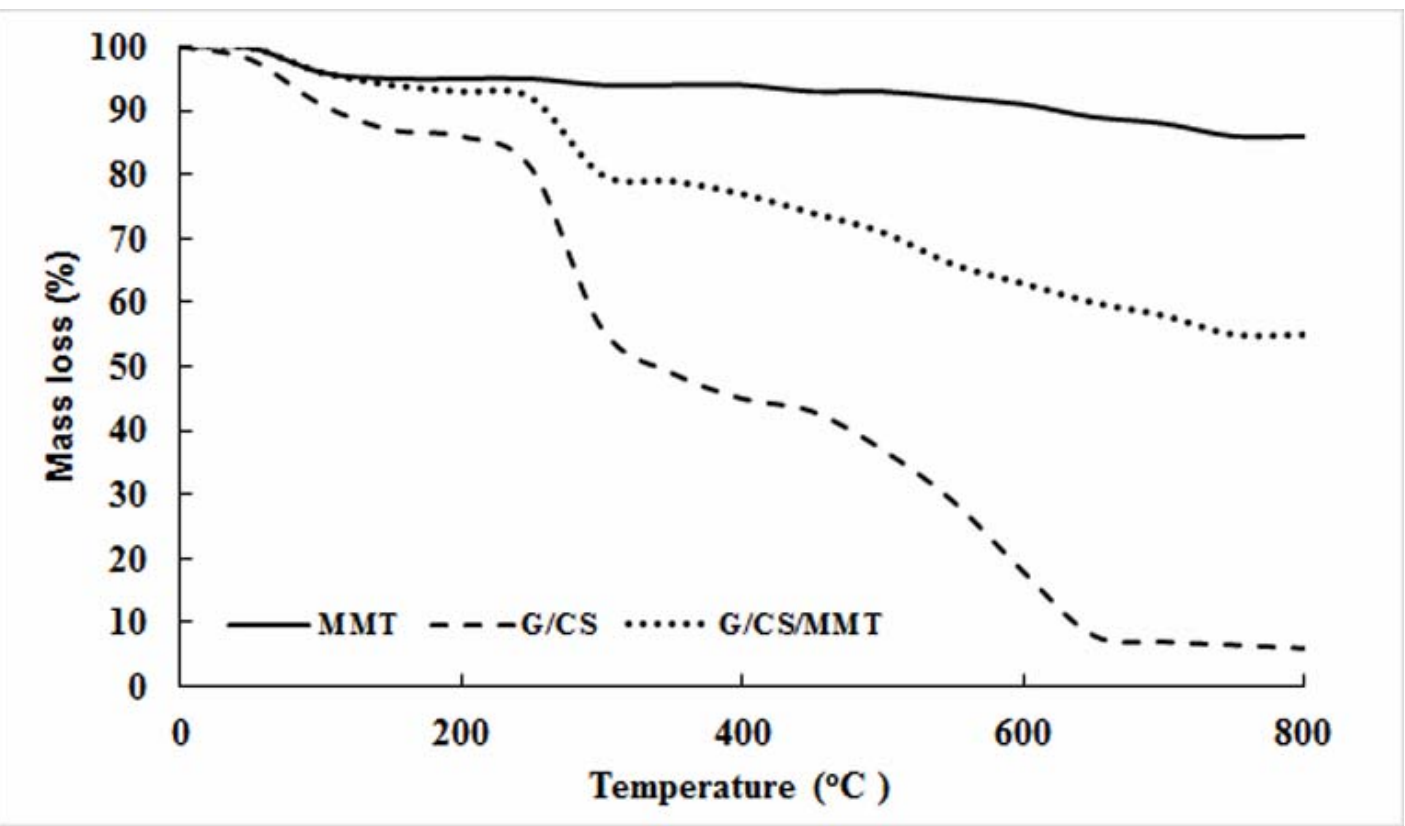

Fig. 3 - Thermogravimetric curves of G/CS, MMT and G/CS/MMT.

The micro/macro architecture of a tissue engineering scaffold is important, since it affects the attachment, migration, proliferation and differentiation of cells. ${ }^{11,12}$ It is important to choose the appropriate pore size to achieve effective bone tissue ingrowth according to the established study. The pore size scale of a scaffold can be varied between 10 to $1000 \mu \mathrm{m} .{ }^{13}$ The large pores are required for migration of cells and for subsequent vascularization following transplantation, while the 
smaller pores are appropriate for the deposition of the extracellular matrix. The pore size distribution curves of the fabricated scaffolds are given in Fig. 4. From the figure, it is evident that the pore size distribution of the G/CS/MMT scaffolds was in the range of 50 to $250 \mu \mathrm{m}$.

The morphology and microstructure of composite scaffolds were studied by SEM. The electron micrographs of the scaffolds indicated an interconnected porous structure with estimated pore sizes ranging from approximately 100 to $175 \mu \mathrm{m}$. This result is in line with the MIP findings. By introducing the MMT into polymer matrix, the pore size range of the scaffold became smaller, as expected (Fig. 5). The aggregate of MMT particles dispersed in the polymer matrix could be clearly seen in Fig. 5, creating a higher surface area for cell adhesion.
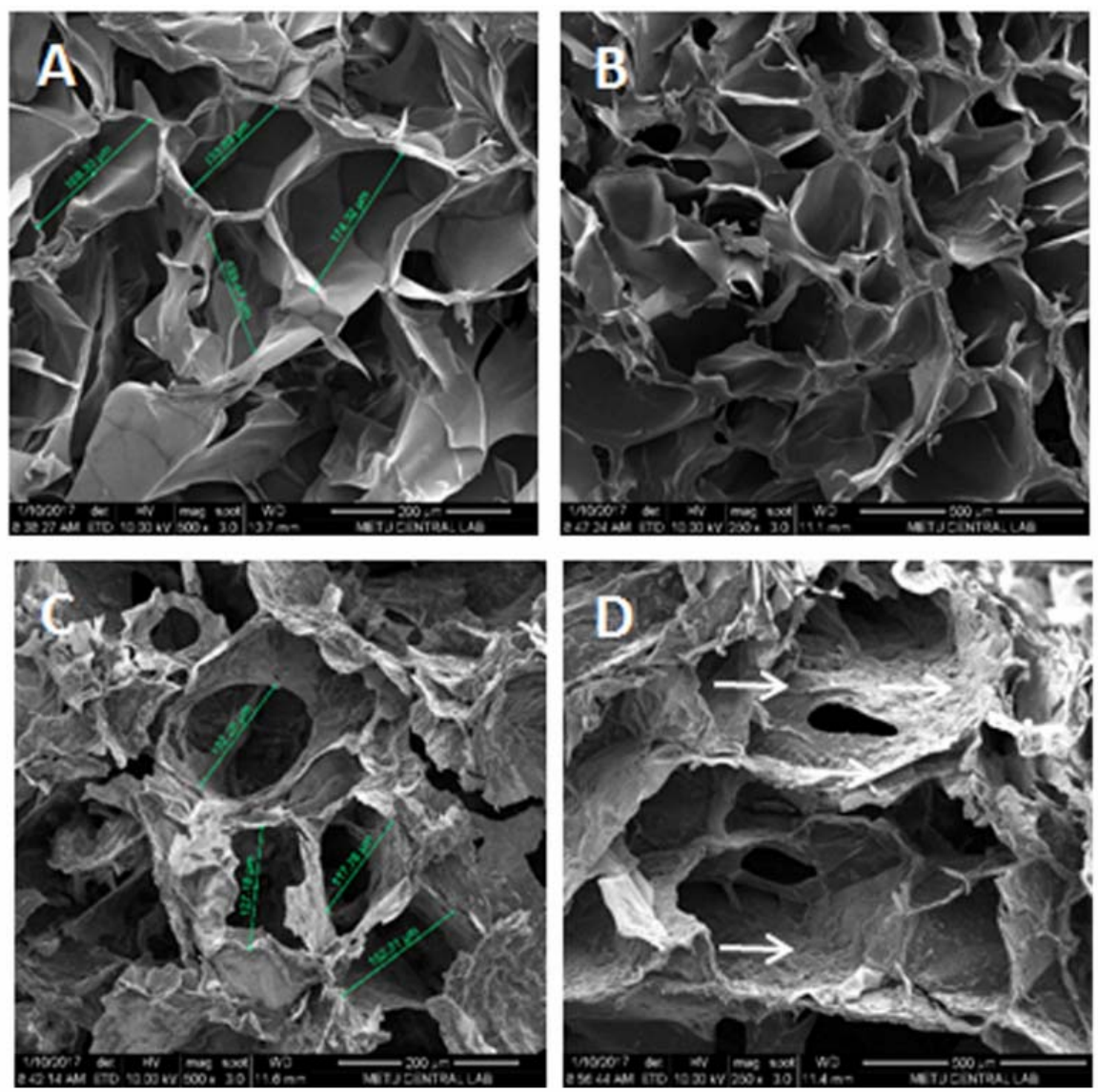

Fig. 4 - Representative SEM micrographs of (A, B) G/CS, and (C, D) G/CS /MMT scaffolds. The arrows indicate MMT particles within the polymeric matrice.

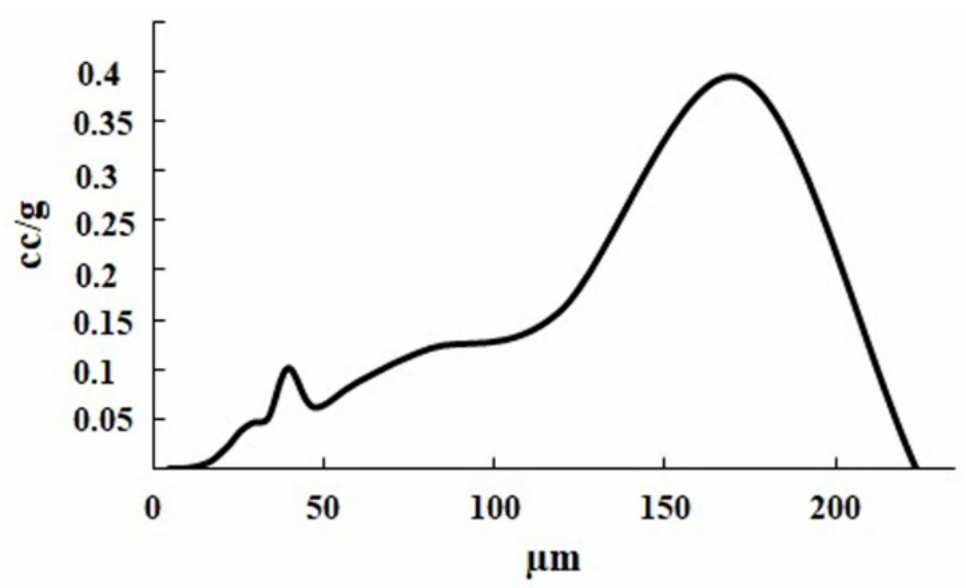

Fig. 5 - The pore size distribution curves of G/CS/MMT composite scaffold. 


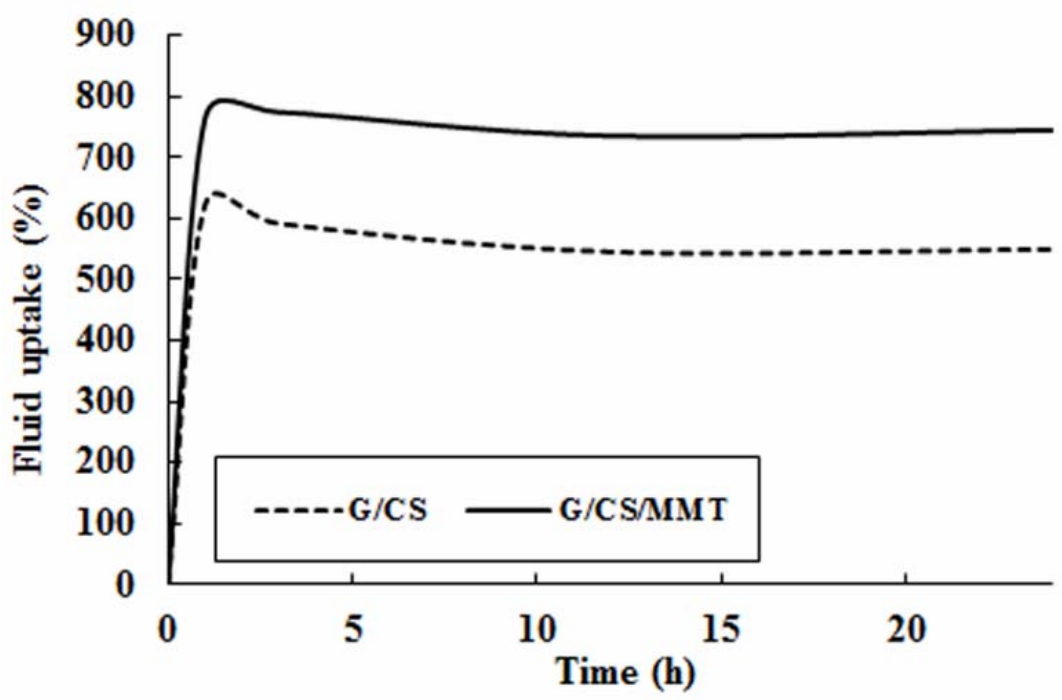

Fig. 6 - Swelling ability of G/CS and G/CS/MMT scaffolds in PBS.

Another expected requirement from osteogenic scaffolds is to possess appropriate mechanical strength which can support new bone formation. ${ }^{14}$ The mechanical strength of the scaffolds was measured as $388.71 \pm 25 \mathrm{~N}$, and $145.19 \pm 0.124 \mathrm{~N}$ for $\mathrm{G} / \mathrm{CS}$ and $\mathrm{G} / \mathrm{CS} / \mathrm{MMT}$, respectively. It was found that the mechanical strength of $\mathrm{G} / \mathrm{CS}$ decreased about $50 \%$ by the addition of MMT to the polymer matrix, while an increase is expected. However, the mechanical strength of the composite was sufficient to resist potential forces after the addition of the clay. This decrease in mechanical strength could probably be due to the higher amount of MMT incorporated, causing a reduction in the crystallinity of the polymer matrix.

Absorption of body fluids and water uptake capacity of the material are also essential for the transport of nutrients and metabolites to the cells. ${ }^{15}$ The swelling capacities of G/CS and G/CS/MMT scaffolds were examined in phosphate buffered saline (Fig. 6). All samples kept their integrity for the duration of the experiments. It was found that the addition of MMT to the polymer matrix resulted in a significant increase in the water uptake capacity of the G/CS. These results suggested that the presence of MMT in the polymer matrix significantly improved the water uptake capacity, thanks to its hydrophobic nature.

The development of bioactive scaffolds is a promising approach. Trace elements including, magnesium, strontium, zinc, boron, etc. present in the bone structure play an important role during the bone development process, by regulating cellular activity through a variety of mechanisms. Therefore, their release from composite materials is useful for supporting bone regeneration. In particular, $\mathrm{Mg}$ is biocompatible, biodegradable, and environmentally friendly, and is the fourth most abundant trace element in the human body after calcium, potassium, and sodium. $\mathrm{Mg}$ has important roles in bone metabolism and has a stimulating effect on new bone formation. ${ }^{16,17}$ It has functions in the cellular processes, such as cell proliferation and differentiation, cell-matrix interactions and vitamin $\mathrm{D}$ metabolism. $\mathrm{Mg}$ deficiency in bone is thought to be a risk factor for osteoporosis. ${ }^{18}$ In this respect, magnesium has a significant role in the preservation of existing bone mass and in the treatment of osteoporosis, and the use of magnesium to enhance bioactivity of materials is a promising route. Based on this approach, MMT was enriched with $\mathrm{Mg}$. The release of $\mathrm{Mg}$ from the scaffold biomaterial was determined by ICP analyses. The concentration of $\mathrm{Mg}$ ions was found to be 2.75, 2.51 and $1.22 \mathrm{mg} / \mathrm{mL}$ at days 1,3 and 7 , respectively. ICP findings revealed that the composite scaffold acts as a release reservoir of $\mathrm{Mg}$ ions, which will have a positive effect on cellular behavior.

\section{CONCLUSIONS}

The development of an osteoactive biomaterial to achieve successful bone tissue engineering scaffold could be a promising approach. In this study, a three-dimensional Mg-enriched G/CS/ MMT scaffold was fabricated using the freeze drying method. The obtained scaffold was 
characterized by a number of chemical, physical and microscopical methods. The data suggest that G/CS/MMT composite scaffold may be a suitable option for bone tissue engineering research. Further studies are planned to increase $\mathrm{Mg}$ content in MMT via enlarging the d-spacing of MMT prior to processing with $\mathrm{Mg}$, and to test the biocompatibility of the composite biomaterial by performing cell culture studies.

Acknowledgments. I thank Professor Y. Murat Elçin from ElçinLab very warmly for advice and support. This study was financially supported by the Ankara University Scientific Research Fund (BAP grant number 16H0430015).

\section{REFERENCES}

1. W. W. Thein-Han and R. D. K. Misra, Acta Biomater., 2009, 5,1182 .

2. P. J. VandeVord, H. W. T Matthew, S. P. DeSilva, L. Mayton, B. Wu and P. H. Wooley, J. Biomed. Mater. Res., 2002, 59, 585.

3. A. S. Carreira, F. A. M. M., Gonçalves, P. V. Mendonça, M. H. Gil, J. F. J. Coelho, Carbohydr. Polym., 2010, 80, 618.
4. R. A. A. Muzzarelli, Oxford: Pergamon Press, 1977, 83, 252.

5. Z. Li, H. R. Ramay, K. D. Hauch, D. Xiao, M. Zhang, Biomaterials, 2005, 26, 3919.

6. A. A. Ana and A. A. Gustavo, Int. J. Pharm., 2017, 523, 441.

7. J. S. Mao, L. G. Zhao, Y. J. Yin, K. D. Yao, Biomaterials, 2003, 24,1067 .

8. T. S. Anirudhan, S. Sandeep, New J. Chem., 2011, 35, 2869.

9. A. Koç Demir, JOTCSA, 2016, 3, 669.

10. K. F. Lin, C. Y. Hsu, T. S. Huang, W. Y. Chiu, Y. H. Lee and T. H. Young, J. Polym. Sci., 2005, 98, 2042.

11. G. Kumar, C. K. Tison, K. Chatterjee, P. S. Pine, J. H. McDaniel, M. L. Salit, M. F. Young and S. C. G. Jr Simon. Biomaterials, 2011, 32, 9188.

12. J. A. Kim, J. Lim, R. Naren, H. Yun, E. K. Park, Acta Biomater., 2016, 44, 155.

13. M. H. Sun, S. Z. Huang, L. H. Chen, Y. Li, X. Y. Yang, Z. Y. Yuan and B. L. Su, Chem. Soc. Rev., 2016, 45, 3479.

14. Y. Chen, D. Kent, M. Bermingham, A. Dehghan-Manshadi, M. Dargusch, Mater. Letter., 2017, 195, 92.

15. Y. Wang, X. Wang, J. Shi, R. Zhu, J. Zhang, Z. Zhang, D. Ma, Y. Hou, F. Lin, J. Yang and M. Mizuno, Scie. Reports, DOI: 10.1038/srep39477.

16. G. Song, Corr. Sci., 2007, 49, 1696.

17. C. Godavitarne, A. Robertson, J. Peters and B. Rogers, Orthopaedics and Trauma, 2017, 31, 5316.

18. R. K. Rude, J. Bone Miner. Res., 1998, 13, 749. 